\title{
Normalization of $\mathrm{Ca}^{2+}$ Signals by Small Oblique Dendrites of CA1 Pyramidal Neurons
}

\author{
Andreas Frick, ${ }^{1,3}$ Jeffrey Magee, ${ }^{2,3}$ Helmut J. Koester, ${ }^{1,3}$ Michele Migliore, ${ }^{4}$ and Daniel Johnston ${ }^{1,3}$ \\ ${ }^{1}$ Division of Neuroscience, Baylor College of Medicine, Houston, Texas 77030, ${ }^{2}$ Neuroscience Center, Louisiana State University Health Science Center, New \\ Orleans, Louisiana 70112, ${ }^{3}$ Marine Biological Laboratory, Woods Hole, Massachusetts 02543, and ${ }^{4}$ Department of Neurobiology, Yale University School of \\ Medicine, New Haven, Connecticut 06520-8001
}

Oblique dendrites of CA1 pyramidal neurons predominate in stratum radiatum and receive $\sim 80 \%$ of the synaptic input from Schaffer collaterals. Despite this fact, most of our understanding of dendritic signal processing in these neurons comes from studies of the main apical dendrite. Using a combination of $\mathrm{Ca}^{2+}$ imaging and whole-cell recording techniques in rat hippocampal slices, we found that the properties of the oblique dendrites differ markedly from those of the main dendrites. These different properties tend to equalize the $\mathrm{Ca}^{2+}$ rise from single action potentials as they backpropagate into the oblique dendrites from the main trunk. Evidence suggests that this normalization of $\mathrm{Ca}^{2+}$ signals results from a higher density of a transient, A-type $\mathrm{K}^{+}$current $\left[I_{\mathrm{K}(\mathrm{A})}\right]$ in the oblique versus the main dendrites. The higher density of $I_{\mathrm{K}(\mathrm{A})}$ may have important implications for our understanding of synaptic integration and plasticity in these structures.

Key words: oblique dendrites; pyramidal neurons; hippocampus; two-photon microscopy; $\mathrm{Ca}^{2+}$ imaging; backpropagating action potentials; 4-AP-sensitive $\mathrm{K}^{+}$channels

\section{Introduction}

Much has been learned recently about the properties and distribution of voltage-gated ion channels in dendrites of CA1 pyramidal neurons (Johnston et al., 1996; Magee et al., 1998; Spruston et al., 1999) and in other cortical neurons (Stuart et al., 1997; Magee, 1999; Häusser et al., 2000). These voltage-gated channels participate in the integration and spread of synaptic inputs impinging on the dendrites and are responsible for the active propagation of action potentials. The action potential in CA1 neurons usually initiates in the axon and is then actively propagated into the apical and basal dendrites (backpropagation) (Spruston et al., 1995; Colbert and Johnston, 1996). The amplitude of this backpropagating action potential, however, decreases in amplitude with distance from the soma and fails to invade certain distal branch points (Spruston et al., 1995; Golding et al., 2002). This decrease in amplitude with distance is attributable in part to a high density of A-type $\mathrm{K}^{+}$channels expressed in distal locations (Hoffman et al., 1997). Under some conditions, the action potential can be initiated directly in dendrites and spread actively and/or passively to more proximal regions of the neuron (Golding and Spruston, 1998; Golding et al., 1999). Both the backpropagating action potential (BAP) and action potentials initiated locally in the dendrites are necessary for the induction of

\footnotetext{
Received Nov. 27, 2002; revised Feb. 3, 2003; accepted Feb. 5, 2003.

This work was supported by the National Institutes of Health (National Institute of Neurological Disorders and Stroke and National Institute of Mental Health) and the Alexander von Humboldt-Foundation (A.F.). We thank Randy Chitwood for constructing Figure 1 and for comments on this manuscript and Nicholas Poolos for helpful discussions. We also thank Rick Gray and Mahmud Haque for writing the acquisition and analysis software. All experiments were conducted at the Marine Biological Laboratory (Woods Hole, MA). We thank the administration and staff of the Marine Biological Laboratory for their help and support.

Correspondence should be addressed to Dr. Daniel Johnston, Division of Neuroscience, Baylor College of Medicine, One Baylor Plaza, Houston, TX 77030. E-mail: dan@mossy.bcm.tmc.edu.

Copyright $\odot 2003$ Society for Neuroscience $\quad 0270-6474 / 03 / 233243-08 \$ 15.00 / 0$
}

certain forms of synaptic plasticity (Magee and Johnston, 1997; Golding et al., 2002; Watanabe et al., 2002).

The most direct information about the properties and distribution of dendritic voltage-gated channels has been gleaned from outside-out or cell-attached patch recordings from dendrites (Stuart and Häusser, 1994; Magee and Johnston, 1995; Hoffman et al., 1997; Magee, 1998; Bekkers, 2000; Korngreen and Sakmann, 2000; Colbert and Pan, 2002; Gasparini and Magee, 2002). These recordings revealed fairly uniform distributions of $\mathrm{Na}^{+}$ channels but very non-uniform distributions of $\mathrm{Ca}^{2+}, \mathrm{K}^{+}$, and $\mathrm{h}$ channels and of channel phosphorylation states. Unfortunately, such channel recordings are typically limited to processes with diameters of greater than $\sim 1 \mu \mathrm{m}$. The vast majority of dendritic surface area of CA1 neurons, however, is taken up by very small oblique dendrites with diameters significantly $<1 \mu \mathrm{m}$ (Bannister and Larkman, 1995a,b; Megias et al., 2001). It has been estimated that $\sim 80 \%$ of Schaffer collateral synapses terminate on these small oblique dendrites, and very little is known about the active properties of these processes (Bannister and Larkman, 1995a; Megias et al., 2001).

We addressed the issue of active properties of oblique dendrites using a combination of $\mathrm{Ca}^{2+}$ imaging and whole-cell recording techniques in CA1 pyramidal neurons. The specific question addressed in the present study was whether oblique dendrites express a high density of A-type $\mathrm{K}^{+}$channels and whether the density of the channels is similar to or different from the density in the apical trunk from which the obliques branch. We found that, for oblique dendrites branching from the proximal part of the apical trunk, the density of $\mathrm{K}^{+}$channels appears to be much higher in the oblique than in its parent dendrite. This higher density of $\mathrm{K}^{+}$channels tends to normalize the rise in $\mathrm{Ca}^{2+}$ from BAPs as they spread into the oblique from the larger parent dendrite. 


\section{Materials and Methods}

Preparation of slice and solutions. Hippocampal slices $(350 \mu \mathrm{m})$ were prepared from 6- to 8-week old Sprague Dawley rats as described previously (Stuart et al., 1993; Hoffman and Johnston, 1998). All experimental procedures were approved by the Animal Research Committee of Baylor College of Medicine and the Marine Biological Laboratory. A Zeiss (Thornwood, NY) Axioskop, fitted with a $60 \times / 0.9$ numerical aperture Olympus Optical (Tokyo, Japan) water-immersion objective and differential interference contrast optics, was used to view slices. The bathing solution contained the following (in $\mathrm{mm}$ ): $125 \mathrm{NaCl}, 2.5 \mathrm{KCl}, 1.25$ $\mathrm{NaH}_{2} \mathrm{PO}_{4}, 25 \mathrm{NaHCO}_{3}, 2 \mathrm{CaCl}_{2}, 1 \mathrm{MgCl}_{2}$, and 25 dextrose (bubbled with $95 \% \mathrm{O}_{2}-5 \% \mathrm{CO}_{2}$ at $\left.34-36^{\circ} \mathrm{C}\right)$. Where specified, one or more of the following drugs was added to the bath solution: 4-aminopyridine (4-AP) (2-4 mM), D,L-APV $(50 \mu \mathrm{M})$, 1,2,3,4-tetrahydro-6-nitro-2,3dioxobenzo $[f]$ quinoxaline-7-sulfonamide (NBQX) (1-5 $\mu \mathrm{M})$, nimodipine $(5 \mu \mathrm{M}), \mathrm{NiCl}_{2}(50-100 \mu \mathrm{M})$, conotoxin MVIIC (3-5 $\left.\mu \mathrm{M}\right), \mathrm{CdCl}_{2}$ $(500 \mu \mathrm{M})$, ryanodine $(20-40 \mu \mathrm{M})$, and $0.05 \%$ ethanol.

Recording and stimulating. Whole-cell recording pipettes (3-5 M $\Omega$ ) were pulled from borosilicate glass and filled with $120 \mathrm{~mm}$ K-methylsulfate, $20 \mathrm{~mm} \mathrm{KCl}, 10 \mathrm{~mm}$ HEPES, $4 \mathrm{~mm} \mathrm{Mg-ATP,} 0.3 \mathrm{~mm}$ Tris-GTP, and $14 \mathrm{~mm}$ phosphocreatine, pH 7.25 with KOH. Bis-fura-2 (CCD experiments; $100 \mu \mathrm{M}$ 4K-Bis-fura-2; Molecular Probes, Eugene, OR) or Oregon Green 488 BAPTA-1 (OGB-1) (multiphoton experiments; $200 \mu \mathrm{M}$; Molecular Probes) was added to the recording pipette daily before experiments. Whole-cell patch-clamp recordings were made from the visually identified CA1 pyramidal somata with an Axon Instruments (Foster City, CA) Axoclamp-2A in "bridge" mode. The resting membrane potential $\left(V_{\mathrm{m}}\right)$ was between -60 and $-74 \mathrm{mV}$. Series resistance for somatic recording was 8-30 $\mathrm{M} \Omega$.

Action potentials were elicited with either somatic depolarizing current injection, usually $2 \mathrm{nA}$ for $2 \mathrm{msec}$, or antidromic stimulation via a stimulating electrode in the alveus. Data are reported as mean \pm SEM.

Local application of tetrodotoxin (TTX) $(2 \mu \mathrm{M})$ and 4-AP (10 mM) to oblique dendrites was accomplished by applying pressure by mouth to a drug-filled patch pipette visually guided to the site of interest (Magee and Johnston, 1997).

Optical imaging. Methods for $\mathrm{Ca}^{2+}$ fluorescence imaging with a CCD camera were similar to those described previously (Lasser-Ross et al., 1991; Magee et al., 1995; Kapur et al., 1998; Yeckel et al., 1999). A Quantix 57 CCD camera (Roper Scientific, Trenton, NJ) with a $535 \times 512$ pixel array and single wavelength $(380 \mathrm{~nm})$ excitation was used with changes in $\left[\mathrm{Ca}^{2+}\right]_{\mathrm{i}}$ quantified by calculating $\Delta F / F$, where $F$ is the fluorescence intensity before stimulation (after subtracting autofluorescence) and $\Delta F$ is the change in fluorescence during neuronal activity (corrected for bleaching). The autofluorescence of the tissue was measured in a region of equal size but adjacent to the dye-filled neuron, in either the dendritic field or the cell body layer, and bleaching was determined by measuring the change in fluorescence at rest (without stimulation). The $\Delta F / F$ measurements were usually repeated three to six times and averaged. Sequential frame rate was $50-100 \mathrm{~Hz}$, and pixels were binned in a $5 \times 5$ array. To adequately visualize the small oblique dendrites, we typically waited at least $20 \mathrm{~min}$ after break-in to allow the indicator dye to diffuse into the smaller branches before recording optical signals. The distance of any given location along the oblique dendrite was calculated by summation of its distance from the branch point and the distance of the branch point to the border of the soma-apical trunk.

For high-resolution, multiphoton imaging of $\mathrm{Ca}^{2+}$ fluorescence transients, we used methods as described previously (Koester et al., 1999). Briefly, we used short pulses from a compact Ti:Sa System (Mai Tai; Spectra Physics, Mountain View, CA) at 890-920 nm and a fast galvanometric scanner (Leica MP RS; Leica Microsystems, Mannheim, Germany) mounted on an upright microscope (Leica DM LFSA) equipped with a $40 \times$ objective $(\mathrm{HCX}$ APO L $40 \times / 0.8 \mathrm{~W})$ to visualize fluorescence changes of OGB-1. Fluorescence transients were recorded in line-scan mode and averaged in time, resulting in a temporal resolution of $4 \mathrm{msec}$. Traces were analyzed using commercial software (Igor Pro; WaveMetrics, Lake Oswego, OR) with in-house algorithms.

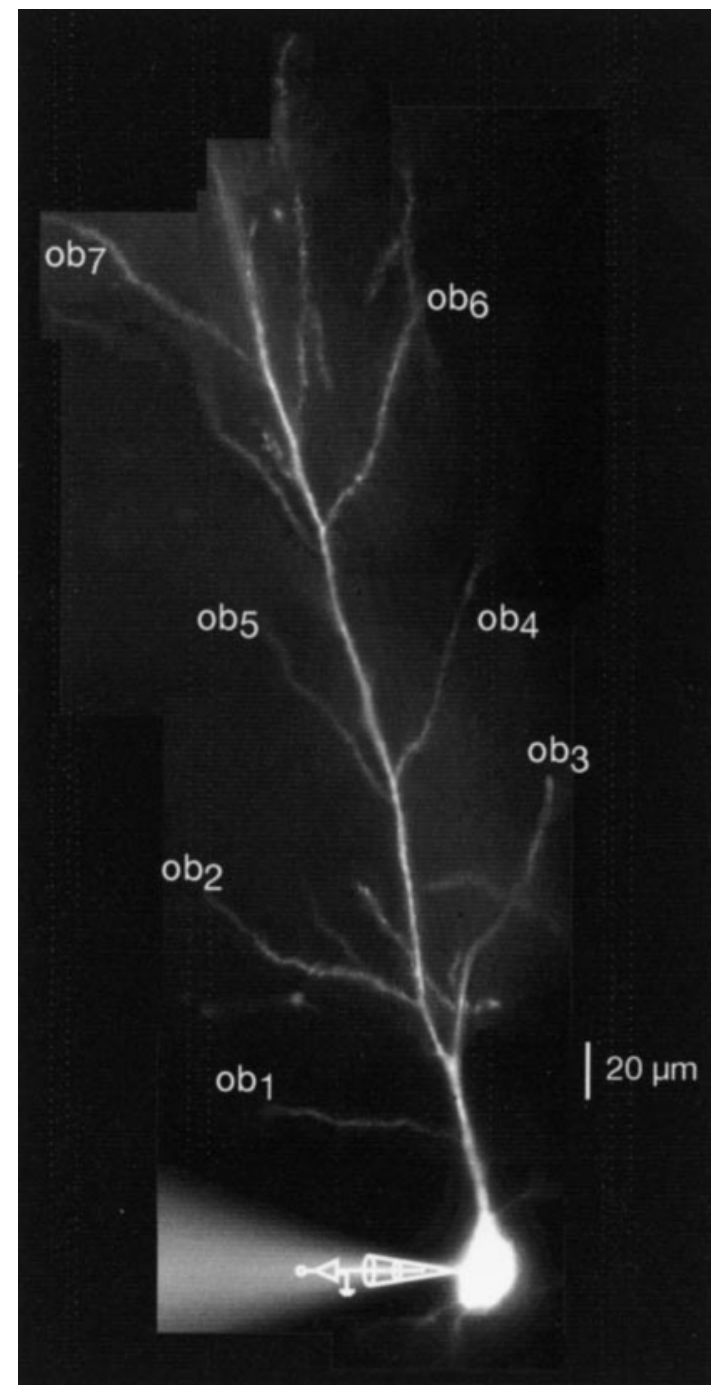

Figure 1. Photomontage of a bis-fura-2-filled CA1 pyramidal neuron illustrates the experimental arrangement. Whole-cell recordings were made in the soma, and several oblique dendrites (ob) are labeled for illustration purposes.

\section{Results}

The general protocol for these experiments is illustrated in Figure 1. Whole-cell recordings were made from the soma of CA1 pyramidal neurons with bis-fura-2- or OGB-1-filled pipettes. Single BAPs were elicited either by brief current injections to the soma or antidromic stimulation to the axons, and the resulting changes in $\left[\mathrm{Ca}^{2+}\right]_{\mathrm{i}}(\Delta F / F)$ were examined over regions of the dendrites with a CCD camera or multiphoton laser scanner. Several oblique dendrites from this particular neuron are indicated in Figure 1.

\section{$\mathrm{Ca}^{2+}$ signals from single BAPs}

Single BAPs elicit rises in $\left[\mathrm{Ca}^{2+}\right]_{\mathrm{i}}$ in primary and secondary dendritic branches that are primarily attributable to the activation of voltage-gated $\mathrm{Ca}^{2+}$ channels (Jaffe et al., 1992; Miyakawa et al., 1992). In the present experiments, these increases were measured as a function of distance from the soma and the type of dendritic branch in 262 neurons. The results from one experiment are illustrated in Figure 2. The oblique branch indicated in Figure $2 \mathrm{~A}$ branched from the main apical trunk at a point $\sim 100 \mu \mathrm{m}$ from the soma. The amplitude of the $\mathrm{Ca}^{2+}$ signal from a single BAP was measured at $\sim 5 \mu \mathrm{m}$ intervals over a region of $\sim 60 \mu \mathrm{m}$ along 
A

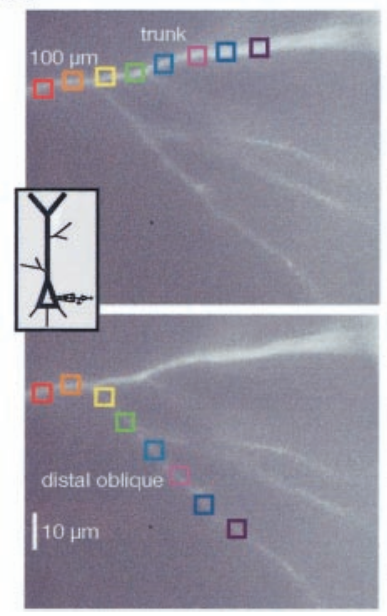

B

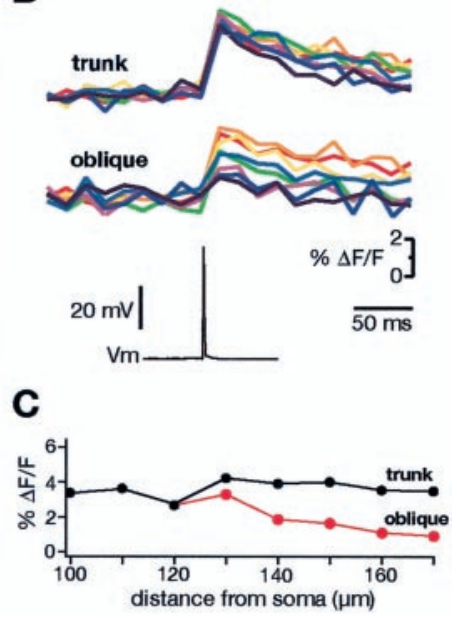

Figure 2. Calcium transients from backpropagating action potentials in the trunk versus a distal oblique dendrite. A, Fluorescence image of the main trunk of the apical dendrite of a CA1 pyramidal neuron is shown with several oblique dendrites branching from the trunk at $>100$ $\mu \mathrm{m}$ from the soma. The inset shows the stimulation and recording configuration. $B$, Changes in $\mathrm{Ca}^{2+}$ (top traces) in response to a backpropagating action potential (bottom trace) were measured as percentage of $\Delta F / F$ simultaneously along the apical trunk and one oblique dendrite. $C$, The percentage of $\Delta F / F$ values are plotted against the distance from soma for this particular neuron. The distance was calculated as the distance from the border of the soma-apical trunk to the branch point, plus the distance from that branch point to the various locations along the oblique dendrite.

the main trunk and similarly along the oblique dendrite. The corresponding $\mathrm{Ca}^{2+}$ signals for each of these locations, and the electrical recording of the BAP measured in the soma are shown in Figure $2 B$. For classification purposes, we arbitrarily separated obliques that originated along the apical trunk within $100 \mu \mathrm{m}$ from the soma and called them proximal obliques, and those that arose from the main trunk at $100 \mu \mathrm{m}$ or more from the soma were called distal obliques.

A typical finding from most of our experiments, and represented in Figure 2, $B$ and $C$, was that, over fairly large distances along the main apical trunk, the $\mathrm{Ca}^{2+}$ signals from single BAPs were remarkably constant. Even in the oblique represented in Figure $2 A$ (which would be classified as a distal oblique), the $\mathrm{Ca}^{2+}$ signals in the first part of the oblique are similar to those in the main trunk. This result is surprising, because the oblique dendrite has a significantly smaller diameter and thereby provides an increasing surface-to-volume $(\mathrm{s} / \mathrm{v})$ ratio at the branch point compared with the main trunk. If all other factors were constant (e.g., BAP amplitude, $\mathrm{Ca}^{2+}$ channel density, $\mathrm{Ca}^{2+}$ channel type, and Ca buffering-extrusion), an increase in the s/v ratio would be expected to yield a larger $\mathrm{Ca}^{2+}$ signal.

Another example of a similar experiment from a proximal oblique is illustrated in Figure $3 A-C$. In this experiment, the peak $\mathrm{Ca}^{2+}$ signals were also surprisingly uniform in amplitude along the main apical trunk and for up to $\sim 40 \mu \mathrm{m}$ along three different proximal obliques. Although exact diameters of these dendrites cannot be known with certainty, it is reasonable to assume that the main apical trunk in this figure had a diameter of $\sim 3 \mu \mathrm{m}$ at the first branch point and that the diameter of the oblique was 0.5-0.8 $\mu \mathrm{m}$ (Bannister and Larkman, 1995b; Megias et al., 2001). Such differences in diameter would produce a large change in the s/v ratio near the branch point (approximately fourfold to sixfold); however, little or no differences in the $\mathrm{Ca}^{2+}$ signals were observed.
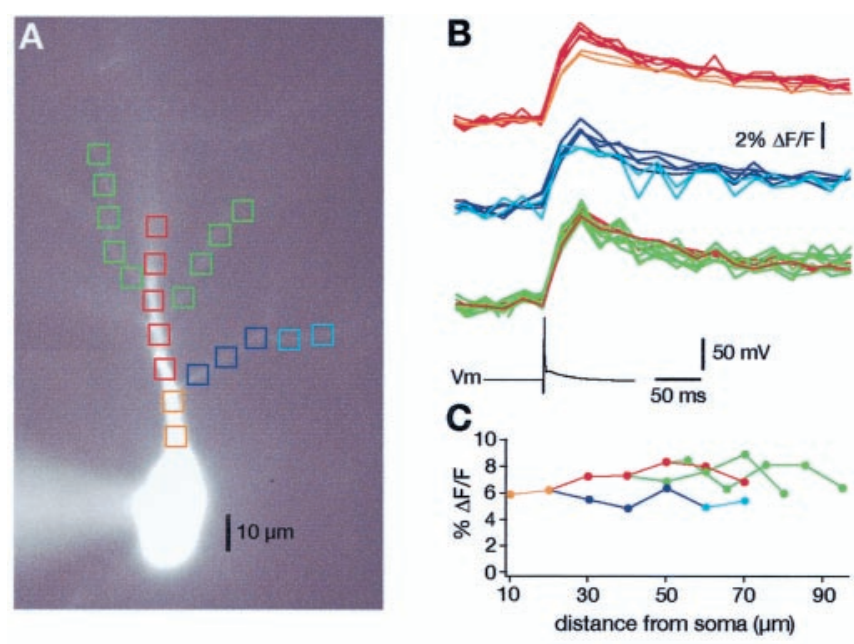

D

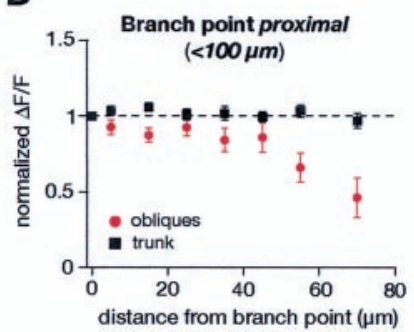

E

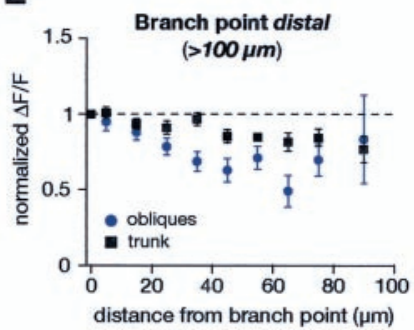

Figure 3. Calcium transients from backpropagating action potentials in the trunk versus proximal oblique dendrites. $A$, Fluorescence image of a CA1 pyramidal neuron with several proximal oblique dendrites. $B$, Changes in $\mathrm{Ca}^{2+}$ (top traces) in response to a backpropagating action potential (bottom trace) were measured as percentage of $\Delta F / F$ along the apical trunk and oblique dendrites. The color of the traces corresponds to the colored boxes in $A$. C, The percentage of $\Delta F / F$ values are plotted against the distance from soma for this particular neuron. $D$, Grouped data of the percentage of $\Delta F / F$ values from 21 proximal oblique dendrites along with the percentage of $\Delta F / F$ values from an equivalent distance along the main trunk. The abscissa represents the distance from the branch points, which were always $<100 \mu \mathrm{m}$ from the soma. $E$, Similar grouped data of the percentage of $\Delta F / F$ values along 19 distal obliques compared with percentage of $\Delta F / F$ values from the main trunk. The abscissa represents the distance from the branch point, which was $>100 \mu \mathrm{m}$ from the soma in all cases.

The results from 40 similar experiments are summarized in Figure 3, $D$ and $E$. Data from a total of 21 proximal and 19 distal obliques are included in the respective graphs. The $\Delta F / F$ values were normalized to the data points obtained by measurements at a given branch point and plotted as function of distance from this branch point. The branch points were typically between 20 and $100 \mu \mathrm{m}$ from the soma in Figure 3D (the most proximal oblique branched $\sim 20 \mu \mathrm{m}$ from the soma) and $\geq 100 \mu \mathrm{m}$ from the soma in Figure $3 E$. One can conclude from the graph that, for at least the first $100-150 \mu \mathrm{m}$ from the soma, the $\mathrm{Ca}^{2+}$ signals from single BAPs are relatively constant in the main apical dendrite. Furthermore, the $\mathrm{Ca}^{2+}$ signals for the first $40-50 \mu \mathrm{m}$ along proximal obliques are similar to those in the main trunk. Even for distal obliques, the $\mathrm{Ca}^{2+}$ signals at the beginning of the oblique are similar to those in the main dendrite.

Although the explanation for the uniform $\mathrm{Ca}^{2+}$ signals is unclear, in previous patch recordings from the main apical trunk of these neurons, the amplitude of the BAP, on average, would be expected to decline by 20-30\% (Golding et al., 2002; Yuan et al., 2002), whereas the density of A-type current would be expected to increase by $200-300 \%$ within the first $100 \mu \mathrm{m}$ of the main apical dendrite (Hoffman et al., 1997). A reasonable hypothesis would therefore be that the larger $\mathrm{K}^{+}$-current and con- 
A

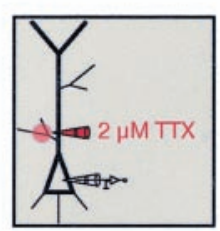

B

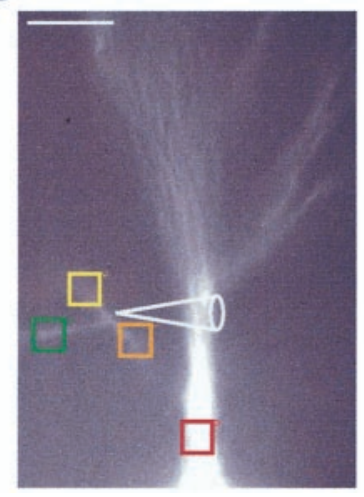

C
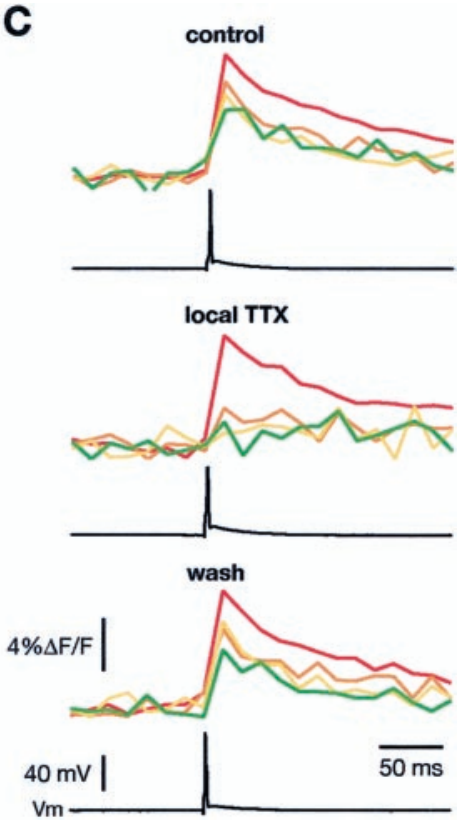

Figure 4. Local application of TTX blocks the backpropagation of action potentials into the oblique dendrites. $A$, Diagram of the stimulating and recording configuration with relative position of TTX-containing pipette. $B$, Fluorescence image of a CA1 pyramidal neuron. The colored boxes correspond to the traces in $\mathrm{C} . \mathrm{C}_{\mathrm{Ca}} \mathrm{Ca}^{2+}$ signals from a single backpropagating action potential in the apical trunk and a proximal oblique dendrite in control (top), after local application of TTX (middle), and after wash of TTX (bottom). During the local application of $2 \mu \mathrm{M}$ TTX to the oblique dendrite, the $\mathrm{Ca}^{2+}$ signals were strongly reduced in the oblique but not in the main trunk. The effect of TTX was reversible (bottom). All traces are averages of six individual traces.

sequent smaller BAP compensate for the increase in the s/v ratio attributable to tapering of the dendrite, so that the $\mathrm{Ca}^{2+}$ signals remain relatively constant. Because little is known about BAPs and $\mathrm{K}^{+}$currents in oblique dendrites, this hypothesis would imply that the amplitude and/or the duration (at half-maximal amplitude) of BAPs in obliques would be smaller than in the main trunk attributable perhaps to a higher $\mathrm{K}^{+}$channel density. An alternative hypothesis would be that the amplitude and duration of BAPs are constant but that either the density of $\mathrm{Ca}^{2+}$ channels is lower in the obliques or that the type of $\mathrm{Ca}^{2+}$ channels varied so that less $\mathrm{Ca}^{2+}$ influx occurred in the obliques with each BAP. A number of different experiments were performed to test these various hypotheses.

\section{Mechanisms of backpropagation and $\mathrm{Ca}^{2+}$ signals in oblique dendrites}

$\mathrm{Na}^{+}$channels in obliques

Previous studies have demonstrated the presence of voltagegated $\mathrm{Na}^{+}$channels in the main apical dendrites of CA1 pyramidal neurons within stratum radiatum (Magee and Johnston, 1995) and that backpropagating action potentials are dependent on $\mathrm{Na}^{+}$channels within this region (Spruston et al., 1995; Magee and Johnston, 1997). Because oblique dendrites are too small for direct recordings, we tested the hypothesis that backpropagation into obliques is also dependent on $\mathrm{Na}^{+}$channels by using local application of TTX. Single BAPs were elicited by current injection to the soma as above, and the $\mathrm{Ca}^{2+}$ signals along the obliques were measured before and after applying TTX locally to the dendrite (Fig. 4A). The results from one experiment are illustrated in Figure 4, $B$ and $C$. Local application of TTX decreased the $\mathrm{Ca}^{2+}$ signals in the obliques by $70 \%$. However, the $\mathrm{Ca}^{2+}$ signals in the

main trunk were decreased by only $12 \%(70.2 \pm 6.2$ vs $12.2 \pm$ $6.3 \% ; n=7 ; p<0.0001$ ) by the same puff application to the oblique, suggesting that the TTX minimally spilled over from the oblique onto the apical dendrite. The effect of TTX was reversible, because the $\mathrm{Ca}^{2+}$ signals fully recovered after wash of the drug (Fig. 4C, wash). These results suggest that BAPs are actively propagated into the obliques via activation of voltage-gated $\mathrm{Na}^{+}$ channels.

\section{$\mathrm{Ca}^{2+}$ channels in obliques}

A variety of voltage-gated $\mathrm{Ca}^{2+}$ channels have been demonstrated in the apical dendrites of CA1 pyramidal neurons. In general, L-type channels $\left(\mathrm{Ca}_{\mathrm{v}} 1.2\right.$ and $\left.\mathrm{Ca}_{\mathrm{v}} 1.3\right)$ are mostly found in the soma and proximal part of the apical dendrite, whereas R-type $\left(\mathrm{Ca}_{\mathrm{v}} 2.3\right)$ and T-type $\left(\mathrm{Ca}_{\mathrm{v}} 3.1-\mathrm{Ca}_{\mathrm{v}} 3.3\right)$ channels are at higher densities in the more distal parts of the apical dendrites (Westenbroek et al., 1990; Johnston et al., 1996; Kavalali et al., 1997) and in spines (Hell et al., 1993; Sabatini and Svoboda, 2000). To determine the types of $\mathrm{Ca}^{2+}$ channels in the oblique dendrites, we measured the changes in the $\mathrm{Ca}^{2+}$ signals from BAPs along the first $20-40 \mu \mathrm{m}$ after applying a number of different $\mathrm{Ca}^{2+}$ channel blockers and compared them with the changes in the trunk 20-40 $\mu \mathrm{m}$ from the branch point (Fig. 5). The results from one experiment are illustrated in Figure 5, $A$ and $B$, and results from all experiments are summarized in Figure $5 C . \mathrm{Ni}^{2+}(50-100 \mu \mathrm{M})$, which blocks $\sim 50 \%$ of R- and T-type channels (Avery and Johnston, 1996), reduced the $\mathrm{Ca}^{2+}$ signals by a similar amount in the trunk and in the oblique [27.5 $\pm 3.0 \%(n=5)$ vs $31.1 \pm 7.9 \%$ $(n=6)$; NS] (Fig. $5 B, C)$. Nimodipine $(5 \mu \mathrm{M})$ also reduced the signals by similar amounts $[13.1 \pm 7.9 \%(n=6)$ vs $10.6 \pm 4.1 \%$ $(n=23)$; NS]. The combination of $\mathrm{Ni}^{2+}(50-100 \mu \mathrm{M})$ and nimodipine $(5 \mu \mathrm{M})$ blocked $\sim 40 \%$ of the $\mathrm{Ca}^{2+}$ signals in both the trunk and the oblique $[37.5 \pm 7.9 \%(n=5)$ vs $41.7 \pm 9.3(n=$ 22)]. Conotoxin MVIIC ( $5 \mu \mathrm{M})$, which blocks N- and P/Q-type channels (McDonough et al., 1996), reduced the signals by $48.8 \pm 2.3 \%$ in the trunk $(n=7)$ and $30.5 \pm 6.4 \%$ in the oblique $(n=7 ; p<0.05)$. The $\mathrm{Ca}^{2+}$ signals could be completely blocked with the nonspecific $\mathrm{Ca}^{2+}$ channel blocker $\mathrm{Cd}^{2+}(500 \mu \mathrm{M})$ $[96.5 \pm 10.2 \%(n=3)$ vs $98.2 \pm 10.6(n=4)]$. Although these results are a first step in determining the source of $\mathrm{Ca}^{2+}$ signals in oblique dendrites, it is not possible to determine quantitatively the relative densities of $\mathrm{Ca}^{2+}$ channels from these results, because there was no control over the BAP amplitude in the obliques during the recordings. Nevertheless, the data suggest a similar distribution of L-, R-, and T-type channels, with N- and P/Q-type being somewhat higher in the main trunk compared with the obliques.

\section{Local application of 4-aminopyridine}

To test the hypothesis that the amplitude of BAPs in oblique dendrites is regulated in part by fast-activating $\mathrm{K}^{+}$channels, we conducted experiments in which we locally applied 4-AP and measured $\mathrm{Ca}^{2+}$ signals from single BAPs before and immediately after 4-AP application. The results of such experiments are illustrated in Figure 6. The local application was performed via a whole-cell patch pipette filled with $10 \mathrm{~mm}$ 4-AP dissolved in extracellular saline and with manual pressure to the pipette. Figure 6, $A$ and $B$, is from an experiment with a proximal oblique. 4-AP produced a large, but local, increase in the $\mathrm{Ca}^{2+}$ signal from the BAP, which could be reversed to control levels by washing out the drug. Summary data from 17 experiments are shown in Figure $6 C$. The results were similar whether the oblique arose from the main dendrite at a distal or proximal location. We always ob- 
A

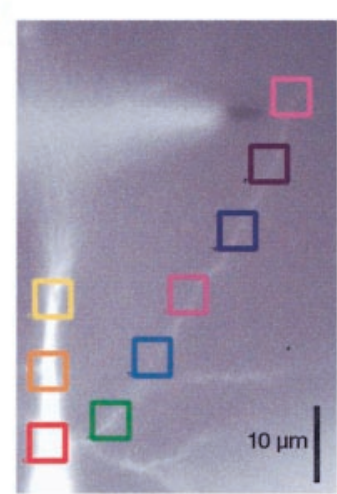

B

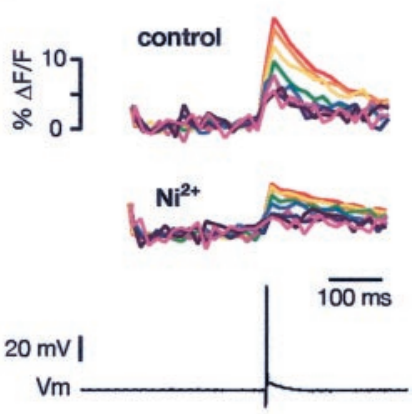

C

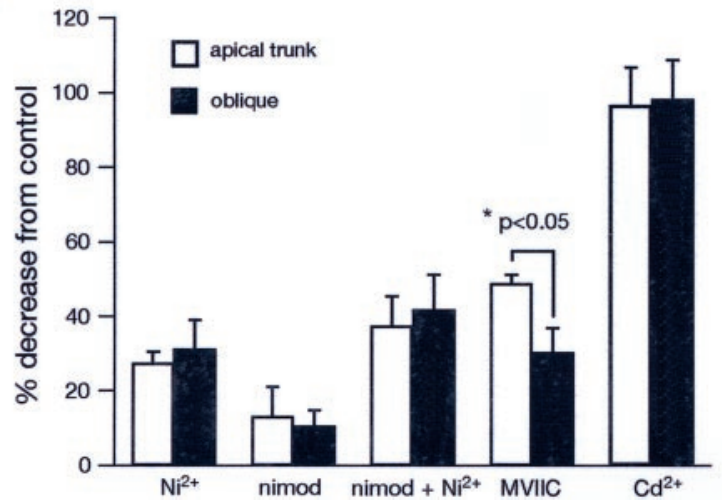

Figure 5. Effects of blockers of voltage-dependent $\mathrm{Ca}^{2+}$ channels on the $\mathrm{Ca}^{2+}$ signals from backpropagating action potentials in oblique dendrites. $A$, A bis-fura-2-filled CA1 neuron. The colored boxes correspond to the traces in $B$. Backpropagating action potentials were evoked by current injection into the soma. $B$, Effect of the T/R-type $\mathrm{Ca}^{2+}$ channel blocker Ni ${ }^{2+}(100 \mu \mathrm{m})$ on the $\mathrm{Ca}^{2+}$ signals along the main trunk and along an oblique dendrite. The colored traces are the $\mathrm{Ca}^{2+}$ signals, and the bottom trace is the action potential measured in the soma. C, Grouped data for the effects of $\mathrm{Ni}^{2+}(50-100 \mu \mathrm{m}$; trunk, $n=5$; oblique, $n=6)$, nimodipine (nimod) (5 $\mu \mathrm{m}$; trunk, $n=6$; oblique, $n=23$ ), $\mathrm{Ni}^{2+}$ plus nimodipine added together (trunk, $n=5$; oblique, $n=22)$, conotoxin MVIIC ( $3-5 \mu \mathrm{m}$; trunk, $n=7$; oblique, $n=7)$, and Cd ${ }^{2+}(500 \mu \mathrm{m}$; trunk, $n=3$; oblique, $n=4$ ). [In separate control experiments, $0.05 \%$ ethanol, the solvent for nimodipine, had no effect on the $\mathrm{Ca}^{2+}$ signals $(n=3)$.]

served an increase in the $\mathrm{Ca}^{2+}$ signal after local application of 4-AP. As a control, we applied 4-AP to the proximal part of the apical dendrite, a region that has been shown previously to have a low density of 4-AP-sensitive $\mathrm{K}^{+}$channels (Hoffman et al., 1997) (Fig. $6 D, E$ ). In seven similar experiments, we found no significant increase in the $\mathrm{Ca}^{2+}$ signals with 4-AP application to the main apical dendrite within $50 \mu \mathrm{M}$ of the soma.

Several recent reports have shown that BAPs can, under certain conditions, trigger $\mathrm{Ca}^{2+}$ release from internal stores (Nakamura et al., 1999). To test whether 4-AP was somehow causing an increase in $\mathrm{Ca}^{2+}$ release from BAPs, we did several control experiments after adding 20-40 $\mu \mathrm{M}$ ryanodine to the bath. We found that ryanodine did not block the increase in $\mathrm{Ca}^{2+}$ from BAPs after local 4-AP application, suggesting that $\mathrm{Ca}^{2+}$ release did not contribute to the $\mathrm{Ca}^{2+}$ signals $(n=3$; data not shown). Nakamura et al. (2002) have reported similar findings.

\section{Bath application of 4-AP}

To further confirm these results, we performed additional experiments in which 4-AP was bath applied. For these experiments, antagonists of NMDA (50 $\mu \mathrm{M}$ D,L-APV) and AMPA (1-5 $\mu \mathrm{M}$
A
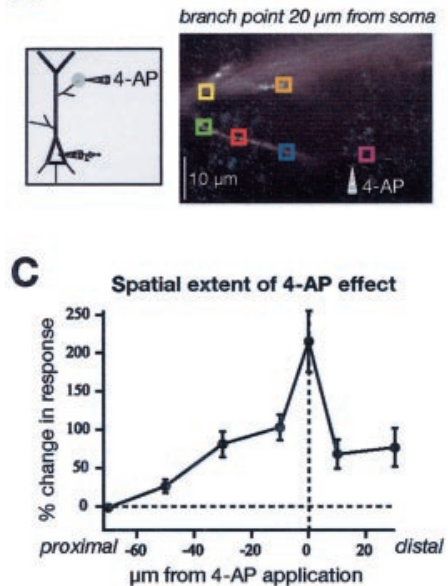

D

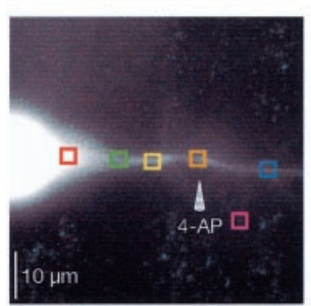

B

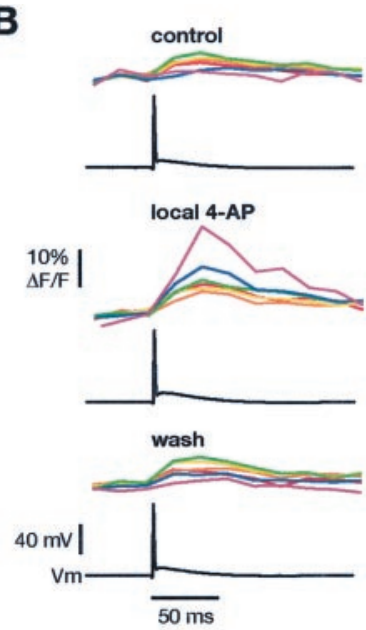

E
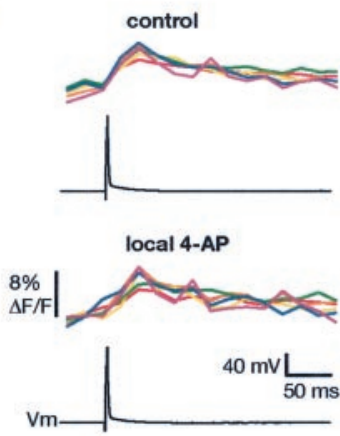

Figure 6. Local application of 4-AP differentially affects oblique versus main dendrites. $A$, Diagram and fluorescence image of CA1 neuron to illustrate experimental configuration. The colored boxes correspond to the traces in $B . B, C^{2+}$ signals at the indicated locations from a single backpropagating action potential in control (top), after local application of 4-AP (middle) to the oblique shown in $A$, and after wash of 4-AP (bottom). C, Grouped data showing the spatial localization of the effect of 4-AP application at proximal and distal oblique dendrites (data combined; $n=17)$. $D$, Similar experiment but local application of $4-A P$ to the main apical trunk of a CA1 neuron. E, Application of the same concentration of 4-AP at the proximal region of the main trunk had only a small effect on the $\mathrm{Ca}^{2+}$ signals.

NBQX) receptors were added to the bath to prevent epileptiform activity. Nevertheless, some neurons responded to the bath application of 4-AP with a small depolarizing hump after the action potential (Fig. $7 B$ ). If this depolarization was pronounced, or even elicited a second action potential, we suppressed it by injecting a strong hyperpolarizing current pulse. Figure $7, A$ and $B$, illustrates the results from one experiment with a proximal oblique. Similar to the results shown in Figure 3, the $\mathrm{Ca}^{2+}$ signals from single BAPs were fairly constant across the main trunk and the proximal obliques. This result is difficult to explain if one assumes uniform action potential amplitude and uniform $\mathrm{Ca}^{2+}$ channel density for the main apical and oblique dendrites. After adding 4-AP to the bath, the $\mathrm{Ca}^{2+}$ signals changed dramatically. The signals in the obliques increased, whereas those in the trunk were relatively unchanged. Figure $7 C$ summarizes the effect of 4 -AP on the $\mathrm{Ca}^{2+}$ signals from BAPs in proximal obliques from 21 experiments.

Bath application of 4-AP was also performed in experiments with more distal obliques ( $n=19$; data not shown). For these dendrites, the change in $\mathrm{Ca}^{2+}$ signals after bath application of 4-AP was similar to the main trunk. In other words, 4-AP produced larger $\mathrm{Ca}^{2+}$ signals in the main trunk as well as the ob- 

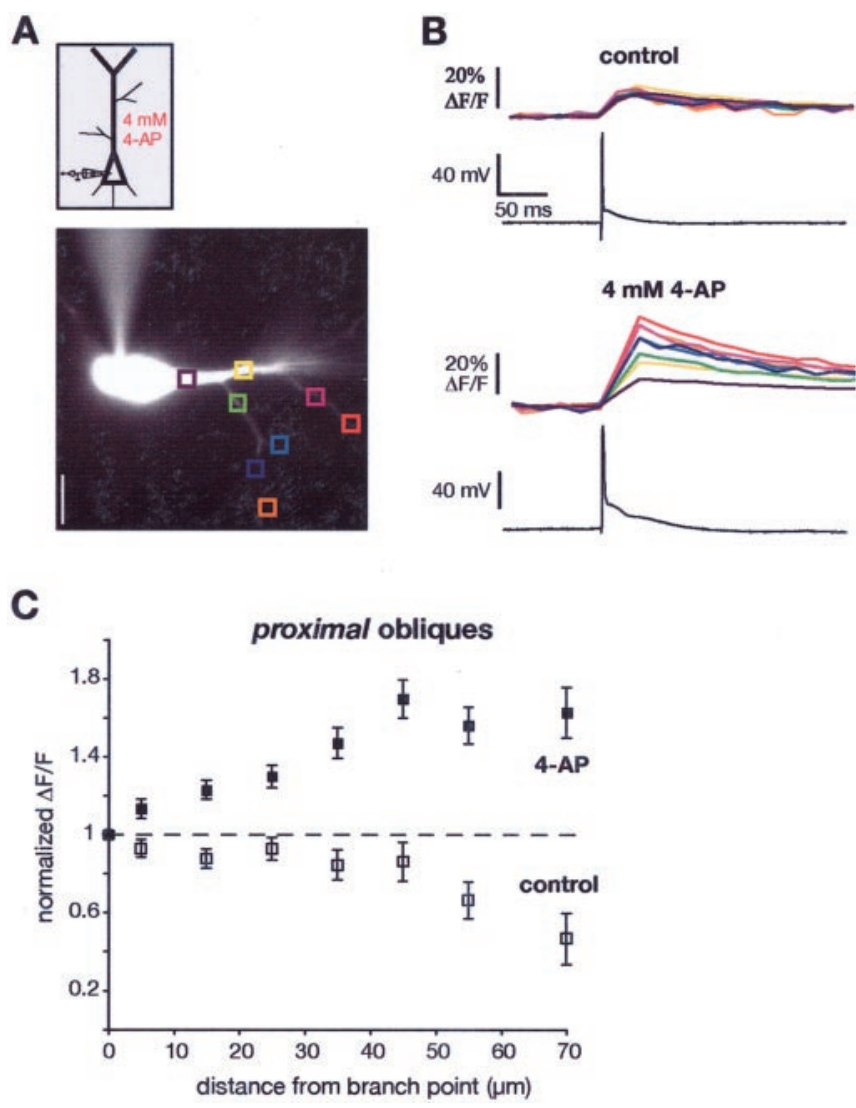

Figure 7. Effects of bath application of 4-AP on dendritic $\mathrm{Ca}^{2+}$ signals. A, Diagram and fluorescence image of a CA1 pyramidal neuron. B, 4-AP ( $4 \mathrm{~mm}$ ) was applied in the bath to block A-type $\mathrm{K}^{+}$channels, and the effects on the $\mathrm{Ca}^{2+}$ signals from a single action potential were compared for the main trunk versus several proximal oblique dendrites. The increase in the $\mathrm{Ca}^{2+}$ signals in the proximal oblique dendrites was much greater than that in the trunk. C, Summary data for 21 experiments.

liques, in keeping with the hypothesis that 4-AP-sensitive $\mathrm{K}^{+}$ channels are expressed in both locations at high densities.

\section{Multiphoton imaging of $\mathrm{Ca}^{2+}$ in oblique dendrites}

Similar experiments were also performed using two-photon $\mathrm{Ca}^{2+}$ imaging of oblique dendrites. Single BAPs were elicited from brief current injections to the soma, and the $\mathrm{Ca}^{2+}$ signals in the main dendrite and at various distances along the obliques were measured in line-scan mode. The $\mathrm{Ca}^{2+}$ signals in the main trunk and in the obliques before and after bath application of 2 mM 4-AP are illustrated in Figure 8. The results are similar to those obtained with the CCD camera. Except for the first 10-20 $\mu \mathrm{m}$ of the oblique, the $\mathrm{Ca}^{2+}$ signals in the oblique under control conditions were similar to those in the main trunk and the branch point but increased significantly after application of 4-AP. Interestingly, at the end of the obliques, the $\mathrm{Ca}^{2+}$ signals were $\sim 15 \%$ larger than $10 \mu \mathrm{m}$ further proximal in control (1.16 $\pm 0.12 \mathrm{vs}$ $0.96 \pm 0.09 ; n=10 ; p<0.05$; data not shown). This phenomenon could be explained by the sealed-end boundary condition.

\section{Discussion}

The principal conclusion from these studies is that the properties of the oblique dendrites, the location for $80 \%$ of Schaffer collateral input, appear to differ significantly from their parent dendrites. The net result of these differences is that the $\mathrm{Ca}^{2+}$ signals from backpropagating action potentials tend to equalize from the
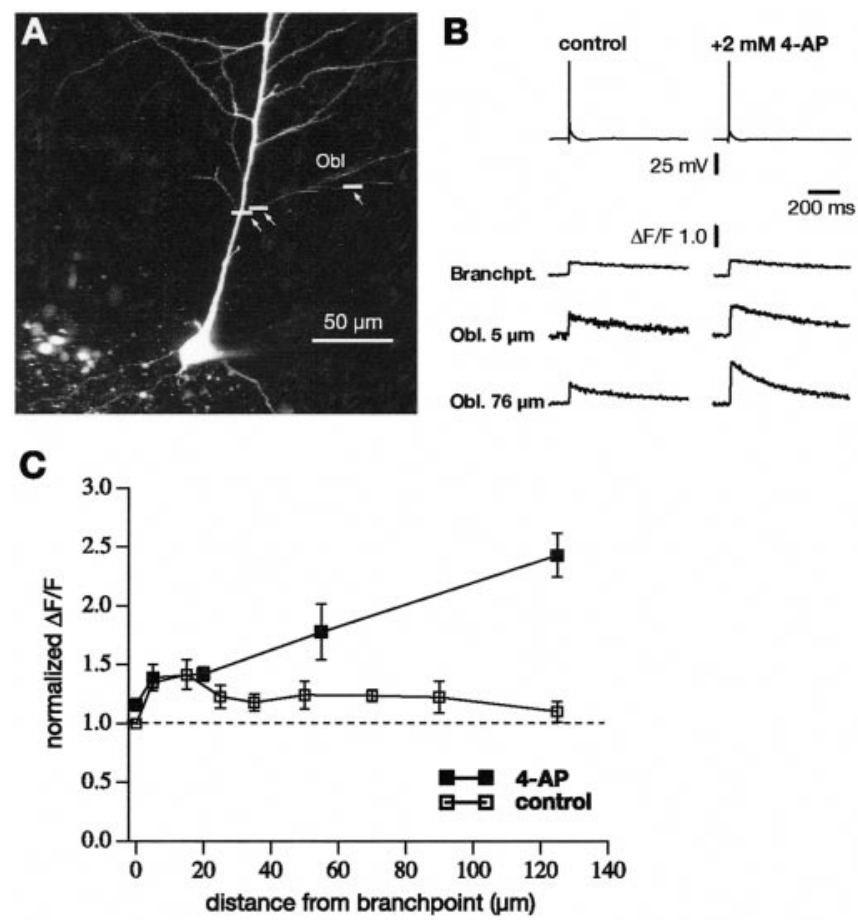

Figure 8. $\mathrm{Ca}^{2+}$ signals from backpropagating action potentials in the main trunk and oblique dendrites measured with multiphoton microscopy. A, Projection through a stack of multiphoton images of a CA1 pyramidal neuron filled via whole-cell recording with the $\mathrm{Ca}^{2+}$ indicator 0GB-1 (200 $\mu \mathrm{m})$. Lines indicate positions of line scans (arrows). B, Single action potentials evoked by brief somatic current injections and their corresponding $\mathrm{Ca}^{2+}$ signals (average of 3 sweeps) in the trunk and at various locations along an oblique before and after the bath application of $2 \mathrm{~mm}$ 4-AP. C, Summary data of 28 experiments for the normalized (to the amplitude in the trunk) amplitude of the $\mathrm{Ca}^{2+}$ signals in trunk and obliques before and after bath application of $2 \mathrm{~mm} 4-\mathrm{AP}$.

parent dendrite into the oblique, despite large differences in the $\mathrm{s} / \mathrm{v}$ ratios across these dendritic segments. We presented several lines of evidence suggesting that the normalization of the $\mathrm{Ca}^{2+}$ signals were attributable principally to larger A-type $\mathrm{K}^{+}$currents in the oblique dendrites. This conclusion was based on the following. (1) BAPs were actively propagated into the obliques, because localized blockade of oblique $\mathrm{Na}^{+}$channels (TTX) decreased oblique BAP-associated $\mathrm{Ca}^{2+}$ signals. (2) Only slight differences were observed in the $\mathrm{Ca}^{2+}$ signal pharmacology. (3) $\mathrm{Ca}^{2+}$ signals from BAPs in the oblique dendrites were increased by either local or widespread $\mathrm{K}^{+}$channel blockade (4-AP). (4) With bath-applied 4-AP, the amplitude of the $\mathrm{Ca}^{2+}$ signals increased from the main trunk into the oblique, similar to what one would predict from the differences in s/v ratio. Together, these results strongly support the conclusion that a 4-AP-sensitive $\mathrm{K}^{+}$ current is normalizing the $\mathrm{Ca}^{2+}$ signals from the main, parent dendrite into the oblique. This normalization appears to occur via a $\mathrm{K}^{+}$current-induced reduction in the amplitude of the BAP as it propagates into the oblique. If the equalization of the $\mathrm{Ca}^{2+}$ signals were instead attributable to a lower density of $\mathrm{Ca}^{2+}$ channels or some other difference in $\mathrm{Ca}^{2+}$ handling in the obliques, one would predict little, if any, effect of local 4-AP application on the oblique.

The above conclusions are most readily apparent from the results with oblique dendrites close $(<50 \mu \mathrm{m})$ to the soma. From a number of previous reports, the amplitude of the BAP in the proximal region of the apical dendrite is $\sim 80-100 \mathrm{mV}$. Also, the density of A-type $\mathrm{K}^{+}$channels is relatively low there compared 
with more distal regions, and the difference in diameter between the main dendrite and the oblique is large $(\sim 3 \mu \mathrm{m}$ for main dendrite vs $<1 \mu \mathrm{m}$ for oblique, resulting in an increase in the $\mathrm{s} / \mathrm{v}$ ratio by more than threefold). Previous studies have shown that decreases in A-type $\mathrm{K}^{+}$channels in the proximal portion of the apical dendrite have relatively little effect on BAP amplitude (Hoffman and Johnston, 1999; Yuan et al., 2002) (Fig. 6D,E). It was thus somewhat surprising that the magnitude of the $\mathrm{Ca}^{2+}$ signals from BAPs were very similar in the parent dendrite and the oblique (given the differences in the s/v ratio), but these signals were dramatically different after local or bath-applied 4-AP. The most parsimonious conclusion from all of our results is that the $80-100 \mathrm{mV}$ action potential in the parent dendrite must be reduced significantly in amplitude and/or duration after entering the oblique dendrite and that this reduction is mediated by 4-APsensitive $\mathrm{K}^{+}$channels. When these channels are reduced in activity, the $\mathrm{Ca}^{2+}$ signals increase in the oblique dendrites as expected from the differences in the $\mathrm{s} / \mathrm{v}$ ratios of the two dendrites and the presumed increases in BAP amplitude in the oblique.

\section{Functional significance}

\section{Consequences for associative synaptic plasticity}

It is interesting to note that density of spines and excitatory synaptic input is low in the first $100 \mu \mathrm{m}$ of the main apical dendrite $(<1$ spine $/ \mu \mathrm{m})$ compared with more distal regions (Megias et al., 2001; Papp et al., 2001). The spine density on all of the oblique dendrites, however, is uniformly high $(>3$ spines/ $\mu \mathrm{m}$ ) (Bannister and Larkman, 1995b; Megias et al., 2001). The contrast between obliques and their parent dendrite is therefore again the greatest for the proximal obliques that initiate along the first $20-100 \mu \mathrm{m}$ of the main apical dendrite. BAPs have been suggested to play a role in certain forms of synaptic plasticity, in particular, with paradigms in which BAPs are paired with smallamplitude synaptic input. The modulation of BAP amplitude, by either appropriately timed synaptic potentials or signal transduction pathways, can regulate the induction of synaptic potentiation (Magee and Johnston, 1997). It is thus tempting to speculate on the reason why the high density of A-type $\mathrm{K}^{+}$channels appears to covary with the density of spines and excitatory synaptic inputs. One hypothesis is that the $\mathrm{K}^{+}$channels function to regulate the induction of synaptic plasticity at the synapses in the vicinity of the channels (Watanabe et al., 2002). This would ensure that, under conditions of low input activity, all synapses would experience similarly low levels of $\mathrm{Ca}^{2+}$ influx, whereas dendritic areas receiving significantly high, properly synchronized input would produce large localized $\mathrm{Ca}^{2+}$ signals appropriate for the induction of associative synaptic plasticity. Furthermore, the channels may play a direct role in regulating the amplitude of the local excitatory input (Ramakers and Storm, 2002), and changes in $\mathrm{K}^{+}$channel function with long-term potentiation may participate in excitability changes that can accompany synaptic potentiation (Frick et al., 2002; Ramakers and Storm, 2002).

Cell-attached patch recordings of A-type $\mathrm{K}^{+}$channels demonstrated that there is a gradient in their density along the main apical dendrites (Hoffman et al., 1997). On the basis of that result, any role for these channels in the induction and/or expression of synaptic plasticity would have predicted differences between proximal and distal synapses. The present results, however, suggest that there may not be any such differences, because so-called proximal synaptic input may actually occur along oblique dendrites, at which the density of A-type $\mathrm{K}^{+}$channels is high enough to regulate the amplitude of BAPs in a similar manner to the more distal regions of the main apical dendrites.

\section{Regulation of channel activity and expression}

Recent biochemical studies may shed some light on the mechanisms responsible for the expression of A-type $\mathrm{K}^{+}$channels in the dendrites of these neurons. The $\mathrm{K}^{+}$channel subunit Kv4.2 is known to be present in dendrites and spines of CA1 neurons, and considerable biochemical and physiological evidence strongly supports Kv4.2 being responsible for at least part of this native dendritic current (Varga et al., 2000; Yuan et al., 2002). In contrast to Kv4.2, other subunits potentially contributing to this current (Kv4.1 and Kv4.3) are expressed only at low levels in these neurons (for review, see Schrader et al., 2002). Kv4.2 is phosphorylated by cAMP-dependent protein kinase (PKA), protein kinase $\mathrm{C}$ (PKC), extracellularly regulated kinase (ERK), and $\mathrm{Ca}^{2+}$ calmodulin dependent kinase II (CaMKII) (Varga et al., 2000). Whereas PKA, PKC, and ERK have effects on these channels by shifting the voltage range of activation (Hoffman and Johnston, 1998; Watanabe et al., 2002), CaMKII activity increases surface expression of Kv4.2 (Varga et al., 2002). $\mathrm{Ca}^{2+}$ influx through NMDA receptors and voltage-gated $\mathrm{Ca}^{2+}$ channels can lead to increased CaMKII activity, which in turn could lead to increases in the density of Kv4.2. Given the presence of CaMKII at postsynaptic densities, such a mechanism for regulating $\mathrm{K}^{+}$channel expression may explain the correlation between $\mathrm{K}^{+}$channels and excitatory synapses discussed above.

In summary, CA1 neurons possess extensive apical dendritic arbors that consist of one or more main dendritic segments and numerous side or oblique branches that originate from virtually anywhere along the main dendrite and that can themselves be up to $150 \mu \mathrm{m}$ in length. In stratum radiatum, $\sim 80 \%$ of Schaffer collateral inputs terminate on these oblique dendrites. The present results suggest that these oblique branches express voltage-gated $\mathrm{Na}^{+}, \mathrm{Ca}^{2+}$, and $\mathrm{K}^{+}$channels and actively backpropagate action potentials. Furthermore, the rise in $\left[\mathrm{Ca}^{2+}\right]_{\mathrm{i}}$ from these BAPs is approximately equal in the larger main dendrite and the smaller oblique dendrite. The results suggest that this equalization is mediated through a higher density of A-type $\mathrm{K}^{+}$channels in the oblique that suppresses the amplitude and/or duration of the action potential and thus reduces the $\mathrm{Ca}^{2+}$ influx. It appears that mechanisms exist in dendrites to adjust the density and/or properties of voltage-gated channels to compensate for changes in the geometry of the dendrites. These results also support numerous theoretical and physiological studies demonstrating the very heterogeneous nature of dendritic properties and compartmentalization of dendritic function (Archie and Mel, 2000).

\section{References}

Archie KA, Mel BW (2000) A model for intradendritic computation of binocular disparity. Nat Neurosci 3:54-63.

Avery RB, Johnston D (1996) Multiple channel types contribute to the lowvoltage-activated calcium current in hippocampal CA3 pyramidal neurons. J Neurosci 16:5567-5582.

Bannister NJ, Larkman AU (1995a) Dendritic morphology of CA1 pyramidal neurones from the rat hippocampus. I. Branching patterns. J Comp Neurol 360:150-160.

Bannister NJ, Larkman AU (1995b) Dendritic morphology of CA1 pyramidal neurones from the rat hippocampus. II. Spine distributions. J Comp Neurol 360:161-171.

Bekkers JM (2000) Distribution and activation of voltage-gated potassium channels in cell-attached and outside-out patches from large layer 5 cortical pyramidal neurons of the rat. J Physiol (Lond) 525:611-620. 
Colbert CM, Johnston D (1996) Axonal action-potential initiation and $\mathrm{Na}^{+}$channel densities in the soma and axon initial segment of subicular pyramidal neurons. J Neurosci 16:6676-6686.

Colbert CM, Pan E (2002) Ion channel properties underlying axonal action potential initiation in pyramidal neurons. Nat Neurosci 5:533-538.

Frick AA, Magee JC, Schexnayder L, Inoue M, Miyakawa H, Johnston D (2002) LTP induction enhances locally the back-propagation of action potentials into the dendrites. Soc Neurosci Abstr 28:443.2.

Gasparini S, Magee JC (2002) Phosphorylation-dependent differences in the activation properties of distal and proximal dendritic $\mathrm{Na}^{+}$channels in rat CA1 hippocampal neurons. J Physiol (Lond) 541:665-672.

Golding NL, Spruston N (1998) Dendritic sodium spikes are variable triggers of axonal action potentials in hippocampal CA1 pyramidal neurons. Neuron 21:1189-1200.

Golding NL, Jung H, Mickus T, Spruston N (1999) Dendritic calcium spike initiation and repolarization are controlled by distinct potassium channel subtypes in CA1 pyramidal neurons. J Neurosci 19:8789-8798.

Golding NL, Staff NP, Spruston N (2002) Dendritic spikes as a mechanism for cooperative long-term potentiation. Nature 418:326-331.

Häusser M, Spruston N, Stuart GJ (2000) Diversity and dynamics of dendritic signaling. Science 290:739-744.

Hell JW, Westenbroek RE, Warner C, Ahlijanian MK, Prystay W, Gilbert MM, Snutch TP, Catterall WA (1993) Identification and differential subcellular localization of the neuronal class C and class D L-type calcium channel alpha-1 subunits. J Cell Biol 123:949-962.

Hoffman DA, Johnston D (1998) Downregulation of transient $\mathrm{K}^{+}$channels in dendrites of hippocampal CA1 pyramidal neurons by activation of PKA and PKC. J Neurosci 18:3521-3528.

Hoffman DA, Johnston D (1999) Neuromodulation of dendritic action potentials. J Neurophysiol 81:408-411.

Hoffman DA, Magee JC, Colbert CM, Johnston D (1997) $\mathrm{K}^{+}$channel regulation of signal propagation in dendrites of hippocampal pyramidal neurons. Nature 387:869-875.

Jaffe DB, Johnston D, Lasser-Ross N, Lisman JE, Miyakawa H, Ross WN (1992) The spread of $\mathrm{Na}^{+}$spikes determines the pattern of dendritic $\mathrm{Ca}^{2+}$ entry into hippocampal neurons. Nature 357:244-246.

Johnston D, Magee JC, Colbert CM, Christie BR (1996) Active properties of neuronal dendrites. Annu Rev Neurosci 19:165-186.

Kapur A, Yeckel MF, Gray R, Johnston D (1998) L-type calcium channels are required for one form of hippocampal mossy fiber LTP. J Neurophysiol 79:2181-2190.

Kavalali ET, Zhuo M, Bito H, Tsien RW (1997) Dendritic $\mathrm{Ca}^{2+}$ channels characterized by recordings from isolated hippocampal dendritic segments. Neuron 18:651-663.

Koester HJ, Baur D, Uhl R, Hell SW (1999) $\mathrm{Ca}^{2+}$ fluorescence imaging with pico- and femtosecond two-photon excitation: signal and photodamage. Biophys J 77:2226-2236.

Korngreen A, Sakmann B (2000) Voltage-gated $\mathrm{K}^{+}$channels in layer 5 neocortical pyramidal neurones from young rats: subtypes and gradients. J Physiol (Lond) 525:621-639.

Lasser-Ross N, Miyakawa H, Lev-Ram V, Young SR, Ross WN (1991) High time resolution fluorescence imaging with a CCD camera. J Neurosci Methods 36:253-261.

Magee J, Hoffman D, Colbert C, Johnston D (1998) Electrical and calcium signaling in dendrites of hippocampal pyramidal neurons. Annu Rev Physiol 60:327-346.

Magee JC (1998) Dendritic hyperpolarization-activated currents modify the integrative properties of hippocampal CA1 pyramidal neurons. J Neurosci 18:7613-7624.

Magee JC (1999) Voltage-gated ion channels in dendrites. In: Dendrites (Stuart G, Spruston N, Hausser M, eds), pp 139-160. Oxford: Oxford UP.

Magee JC, Johnston D (1995) Characterization of single voltage-gated $\mathrm{Na}^{+}$ and $\mathrm{Ca}^{2+}$ channels in apical dendrites of rat CA1 pyramidal neurons. J Physiol (Lond) 487:67-90.

Magee JC, Johnston D (1997) A synaptically controlled, associative signal for Hebbian plasticity in hippocampal neurons. Science 275:209-213.
Magee JC, Christofi G, Miyakawa H, Christie B, Lasser-Ross N, Johnston D (1995) Subthreshold synaptic activation of voltage-gated $\mathrm{Ca}^{2+}$ channels mediates a localized $\mathrm{Ca}^{2+}$ influx into the dendrites of hippocampal pyramidal neurons. J Neurophysiol 74:1335-1342.

McDonough SI, Swartz KJ, Mintz IM, Boland LM, Bean BP (1996) Inhibition of calcium channels in rat central and peripheral neurons by omegaconotoxin MVIIC. J Neurosci 16:2612-2623.

Megias M, Emri Z, Freund TF, Gulyas AI (2001) Total number and distribution of inhibitory and excitatory synapses on hippocampal CA1 pyramidal cells. Neuroscience 102:527-540.

Miyakawa H, Ross WN, Jaffe D, Callaway JC, Lasser-Ross N, Lisman JE, Johnston D (1992) Synaptically activated increases in $\mathrm{Ca}^{2+}$ concentration in hippocampal CA1 pyramidal cells are primarily due to voltagegated $\mathrm{Ca}^{2+}$ channels. Neuron 9:1163-1173.

Nakamura T, Barbara JG, Nakamura K, Ross WN (1999) Synergistic release of $\mathrm{Ca}^{2+}$ from IP3-sensitive stores evoked by synaptic activation of mGluRs paired with backpropagating action potentials. Neuron 24:727-737.

Nakamura T, Lasser-Ross N, Nakamura K, Ross WN (2002) Spatial segregation and interaction of calcium signalling mechanisms in rat hippocampal CA1 pyramidal neurons. J Physiol (Lond) 543:465-480.

Papp E, Leinekugel X, Henze DA, Lee J, Buzsaki G (2001) The apical shaft of CA1 pyramidal cells is under GABAergic interneuronal control. Neuroscience 102:715-721.

Ramakers GM, Storm JF (2002) A postsynaptic transient $\mathrm{K}^{+}$current modulated by arachidonic acid regulates synaptic integration and threshold for LTP induction in hippocampal pyramidal cells. Proc Natl Acad Sci USA 99:10144-10149.

Sabatini BL, Svoboda K (2000) Analysis of calcium channels in single spines using optical fluctuation analysis. Nature 408:589-593.

Schrader LA, Anderson AE, Varga AW, Levy M, Sweatt DJ (2002) The other half of Hebb: $\mathrm{K}^{+}$channels and the regulation of neuronal excitability in the hippocampus. Mol Neurobiol 25:51-66.

Spruston N, Schiller Y, Stuart G, Sakmann B (1995) Activity-dependent action potential invasion and calcium influx into hippocampal CA1 dendrites. Science 268:297-300.

Spruston N, Stuart G, Häusser M (1999) Dendritic integration. In: Dendrites (Stuart G, Spruston N, Häusser M, eds), pp 231-270. Oxford: Oxford UP.

Stuart G, Häusser M (1994) Initiation and spread of sodium action potentials in cerebellar Purkinje cells. Neuron 13:703-712.

Stuart G, Spruston N, Sakmann B, Häusser M (1997) Action potential initiation and backpropagation in neurons of the mammalian CNS. Trends Neurosci 20:125-131.

Stuart GJ, Dodt HU, Sakmann B (1993) Patch-clamp recordings from the soma and dendrites of neurones in brain slices using infrared video microscopy. Pflügers Arch 423:511-518.

Varga AW, Anderson AE, Adams JP, Vogel H, Sweatt JD (2000) Inputspecific immunolocalization of differentially phosphorylated Kv4.2 in the mouse brain. Learn Mem 7:321-332.

Varga AW, Yuan LL, Anderson AE, Johnston D, Sweatt JD (2002) CaMKII regulates potassium channel stability and cell surface expression. Soc Neursci Abstr 28:149.12.

Watanabe S, Hoffman DA, Migliore M, Johnston D (2002) Dendritic $\mathrm{K}^{+}$ channels contribute to spike-timing dependent long-term potentiation in hippocampal pyramidal neurons. Proc Natl Acad Sci USA 99:8366-8371.

Westenbroek RE, Ahlijanian MK, Catterall WA (1990) Clustering of L-type $\mathrm{Ca}^{2+}$ channels at the base of major dendrites in hippocampal pyramidal neurons. Nature 347:281-284.

Yeckel MF, Kapur A, Johnston D (1999) Multiple forms of LTP in hippocampal CA3 neurons use a common postsynaptic mechanism. Nat Neurosci 2:625-633.

Yuan LL, Adams JP, Swank M, Sweatt JD, Johnston D (2002) Protein kinase modulation of dendritic $\mathrm{K}^{+}$channels in hippocampus involves a mitogen-activated protein kinase pathway. J Neurosci 22:4860-4868. 